\title{
Understanding The Experiences of Youth In Collaborative Technical Workplaces
}

William Easley

University of Maryland, Baltimore

County

Baltimore, MD 21250, USA

easley1@umbc.edu
Permission to make digital or hard copies of part or all of this work for personal or classroom use is granted without fee provided that copies are not made or distributed for profit or commercial advantage and that copies bear this notice and the full citation on the first page. Copyrights for third-party components of this work must be honored. For all other uses, contact the owner/author(s).

Copyright held by the owner/author(s).

CSCW' 18 Companion, November 3-7, 2018, Jersey City, NJ, USA ACM 978-1-4503-6018-0/18/11.

https://doi.org/10.1145/3272973.3272987

\begin{abstract}
In many communities, a limited number of job opportunities exist which allow youth to practice valuable technical and collaborative skills necessary for future employment in competitive and high-paying fields. While prior research has examined youths' technology use in various settings such as home or school, my dissertation research seeks to understand how youth use technology to collaborate at work. The goal of this work is to understand the challenges faced by youth as they transition into technical workplaces and to investigate how we can better prepare them for collaborative work through technological and interpersonal interventions.
\end{abstract}

\section{Author Keywords}

Youth; after-school employment; workplace collaboration

\section{Context and Motivation}

Employment has been noted to have many positive impacts on youth development. These benefits include the development of employable skills [5, 7], and a positive influence on long-term careers [5]. Despite these benefits, few employment opportunities exist in communities such as Baltimore, Maryland [10] for youth to develop and practice valuable technical and collaborative skills. To address the lack of local opportunities in Baltimore, the Digital Harbor Foundation $^{1}$ (DHF), a nationally recognized educational non-profit,

\footnotetext{
${ }^{1}$ https://www.digitalharbor.org/
} 
opened an after-school 3D print shop ${ }^{2}$ for youth from diverse backgrounds. My dissertation research is situated at DHF and seeks to explore the experiences of youth employees performing collaborative technical work.

While prior work has explored youth use of technology (e.g., $[6,8])$ in home/school contexts and identified collaborative challenges faced by employees in technical workplaces (e.g., [1, 3]), little is known about how youth use technology to collaborate in the workplace. To address this gap, my research seeks to understand: 1) What challenges do youth face in collaborative workplaces? 2) What are the strategies/workarounds employed by youth to promote successful collaboration? and 3) Which challenges collaborating can be mitigated/addressed through technological interventions and which challenges are best addressed through interpersonal solutions?

\section{Research Design}

To investigate the experiences of youth in collaborative technical workplaces, I have conducted one year of exploratory field work at the DHF 3D print shop in Baltimore, Maryland, USA. During this period, the print shop has employed eight youth (ages 15-18) after-school. I was engaged with the print shop as a participant observer, seeking to understand the challenges encountered by youth in this setting. In my participant observer role, I regularly visited the site to observe and record field notes. I conducted formal interviews with youth and had informal discussions to validate my findings. I also participated in weekly meetings with the print shop's management to understand more about the logistics involved with running the print shop. Finally, I participated in monthly print shop meetings with both management and youth employees present where I occasionally conducted focus groups and participatory design

\footnotetext{
${ }^{2} \mathrm{http}: / /$ printshop.digitalharbor.org/
}

sessions. In addition to these methods, our research team has also had access to print shop's collaborative tools. These include a Google Spreadsheet called the "Jobs Dashboard" (Figure 1) which is an in-house developed workflow management system, and the print shop's Slack workspace which is used to share structured progress updates (called stand ups) and also for informal questions and conversations. This approach has afforded me with valuable insight into many of the challenges faced by youth in collaborative technical settings and has informed the direction of my current and future research.

Study on Youth Collaboration in a 3D Print Shop

I found that challenges adapting to the mechanics of collaborative work have posed greater threats to the print shop's overall productivity than learning curves associated with operating the various fabrication tools needed for work. One challenging area in particular has been performing handoffs between shifts. Handoffs between youth employees are necessary in this environment because most work performed (3D printing, 3D scanning, 3D design) takes longer than an average work shift (two hours). After noting several instances where unsuccessful handoffs lead to incorrect or incomplete work, I investigated the factors leading to successful and unsuccessful handoffs in the print shop as well as the various techniques used by youth employees to support them. Unlike much of prior research which explores handoffs in safety critical settings where the work is continuously monitored (e.g., [2, 11, 9]) by experienced employees, handoffs in the print shop happen asynchronously by employees who are new to the workforce.

Like prior research, I found that sufficient awareness of ongoing activities [4] was necessary for successful collaboration. While the print shop uses two collaborative tools Slack and the Jobs Dashboard - to promote awareness of 

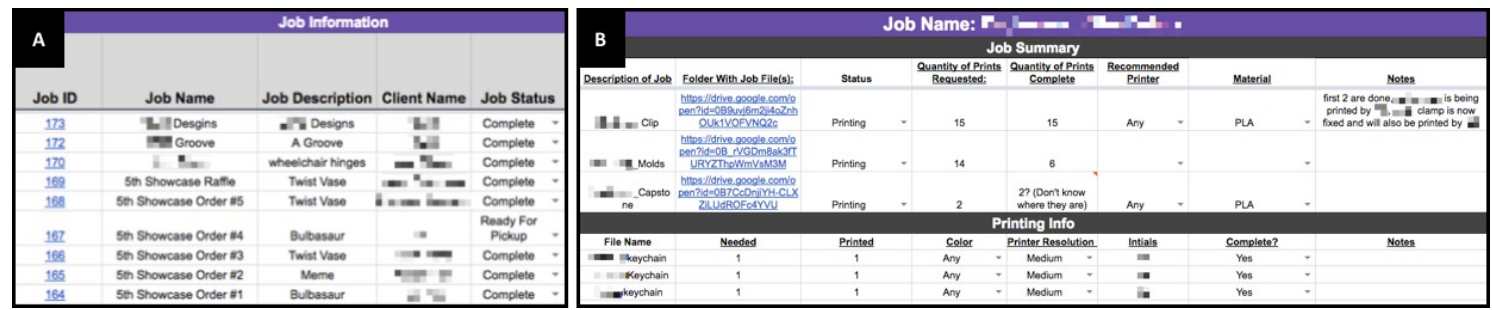

Figure 1: The Jobs Dashboard was a tool created by the print shop to promote awareness of ongoing workflows. It provides both an overview of all ongoing work (A) and job specific details (B).

work through asynchronous handoffs, I found that neither tool was used by youth employees as anticipated by management. Instead of always documenting their work and relying solely on these tools for information, youth would often rely on alternative strategies such as counting physical artifacts (to determine what needed to be done) or asking their manager for status updates (on work started by their peers) to get work done. After looking more closely at examples of jobs with successful and unsuccessful handoffs, I found that the manager's presence, the physical characteristics of 3D prints (size and recognizability of the object), and the youth perspective that only completed prints should be documented were all factors which contributed to whether handoffs were successful.

Future Study on Youth Collaboration Across Multiple Settings After spending one year in the field at my research site, I now have a solid understanding of the work performed in the 3D print shop as well as many of the challenges encountered and strategies employed by youth in this setting. Moving forward, I plan to expand on my current work at the print shop by examining youth collaboration in a second setting; a web shop that will also be located at the DHF. Because the work in each setting is so different, activities - such as documenting work, or utilizing communication tools - supporting awareness may also be different. After the web shop opens, I plan examine the utilization of collaborative tools (e.g., version control software vs. the Jobs Dashboard for workflow management, or Slack) to promote awareness in each setting.

\section{Expected Contributions}

My dissertation research will contribute to a better understanding of how youth perceive and approach collaborative work. The findings of this work will also contribute to our understanding of how we can better prepare youth with experience and skills necessary for the modern workforce where they are likely to collaborate asynchronously as part of a geographically distributed team. This understanding will help to inform the design of new collaborative technologies which support awareness in the workplace.

\section{Expected Benefits from Participation}

I plan to defend my dissertation proposal (October 2018) before the CSCW Doctoral Colloquium will take place. If given the opportunity to participate, I believe that this experience will provide me with an invaluable opportunity to engage with both my peers and senior researchers within the field. I believe that my research would benefit greatly from 
additional perspectives on my approach to this research, and also from others' thoughts on which factors make my research interesting or unique. I would appreciate feedback from others on the presentation of my research and advice on how my work can be better presented to the CSCW community. Finally, I believe that participating will lead to conversations which inspire new ideas and directions for my research better.

\section{Acknowledgements}

This material is based on work supported by the National Science Foundation under Grant No. EEC-1623490.

\section{REFERENCES}

1. Andrew Begel and Beth Simon. 2008. Novice Software Developers, All over Again. In Proceedings of the Fourth International Workshop on Computing Education Research (ICER '08). ACM, New York, NY, USA, 3-14.

2. Richard Bentley, John A Hughes, David Randall, Tom Rodden, Peter Sawyer, Dan Shapiro, and lan Sommerville. 1992. Ethnographically-informed systems design for air traffic control. In Proceedings of the 1992 ACM conference on Computer-supported cooperative work. ACM, 123-129.

3. Bill Curtis, Herb Krasner, and Neil Iscoe. 1988. A Field Study of the Software Design Process for Large Systems. Commun. ACM 31, 11 (Nov. 1988), 1268-1287.

4. Paul Dourish and Victoria Bellotti. 1992. Awareness and Coordination in Shared Workspaces. Proc. Intl. Conf. on Computer-Supported Cooperative Work November (1992), 107-114.
5. Alexander Gelber, Adam Isen, and Judd B Kessler. 2014. The effects of youth employment: Evidence from new york city summer youth employment program lotteries. Technical Report.

6. Rebecca E Grinter and Leysia Palen. 2002. Instant messaging in teen life. In Proceedings of the 2002 ACM conference on Computer supported cooperative work. ACM, 21-30.

7. Georgia Hall, Laura Israel, and Joyce Shortt. 2004. It's About Time! A Look at Out-of-School Time for Urban Teens. Technical Report. National Institute on Out-of-School Time.

8. Paul Mihailidis. 2014. A tethered generation: Exploring the role of mobile phones in the daily life of young people. Mobile Media \& Communication 2, 1 (2014), 58-72.

9. Emily S Patterson and David D Woods. 2001. Shift changes, updates, and the on-call architecture in space shuttle mission control. Computer Supported Cooperative Work (CSCW) 10, 3 (2001), 317-346.

10. Andrea Payne. 2009. A Young Workforce At Risk: Reconnecting Out-of-School and Out-of-Work Youth in Maryland. Technical Report.

11. Xiaomu Zhou, Mark S Ackerman, and Kai Zheng. 2009. I just don't know why it's gone: maintaining informal information use in inpatient care. In Proceedings of the SIGCHI Conference on Human Factors in Computing Systems. ACM, 2061-2070. 